\title{
La noción de tradición y la reflexión sobre la historia de la filosofía mexicana
}

Roberto Israel Rodríguez Soriano

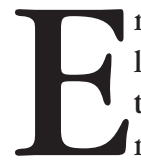

n este ensayo daré argumentos para sostener que la reflexión sobre la historia de la filosofía mexicana reviste suma importancia en nuestro quehacer -inserto en una tradición específica- como filósofos mexicanos. De acuerdo con el objetivo anterior, lo primero será plantear elementos teóricos para precisar el concepto de tradición, como un concepto con sustento ontológico y epistemológico que incide directamente no sólo en nuestro quehacer filosófico, sino en nuestra configuración de la realidad. Para ello, seguiré algunos planteamientos de la analítica existenciaria de Heidegger, así como algunas ideas de la teoría metafísica y hermenéutica de Gadamer.

Una vez establecido lo anterior, desarrollaré los nexos entre el concepto de tradición y la reflexión sobre la historia de la filosofía, en específico, la mexicana.

\section{La tradición}

Martin Heidegger en Ser y tiempo señala que el ser ahí (Dasein) es el único ente que puede plantearse la pregunta por el ser. Indicó que éste, el ser ahí, tiene una serie de rasgos particulares de sí mismo. El ser ahí o Dasein no se limita a ponerse delante de otros entes; el ser ahí, propiamente el humano, no es el sujeto, no es el ente privilegiado que pone el ser, sino simplemente el ente que no sólo es como los demás entes, sino que "está" en relación con el ser, y tiene como característica esencial la comprensión del ser.

Heidegger descubre que la esencia de este ente, del ser ahí, es la existencia, es decir, que no está determinado, que su esencia es, precisamente, su posibilidad. Su ser está siempre en juego. Siempre es algo no dado. Se afirma de este modo que el ser ahí es su posibilidad, posibilidad existencial. Esto es, 
maneras posibles de existir concretamente. El ser ahí se determina como ente, en cada caso, partiendo de una posibilidad que él es. Entonces, cualquiera de los otros entes son, pero no existen. Sólo el humano, el Dasein, existe.

Asimismo, Heidegger señala que la primera determinación fundamental del ser ahí o Dasein es ser en el mundo, o mejor, estar en el mundo, ${ }^{1}$ y una forma de estar en el mundo es la comprensión, que consiste en la aprehensión del mundo. El ser ahí, por la comprensión, se encuentra siempre con que ha revelado, de una cierta manera, al ser del mundo y a su propio ser. El Dasein alcanza su ser en la comprensión, por su aprehensión de sí mismo hacia lo posible. Éste, siempre ve hacia el porvenir y se comprende de frente a su poder ser. La comprensión se mueve en el dominio de sus posibilidades. El carácter mismo de la comprensión es denominado por Heidegger pro-yecto. ${ }^{2}$ Proyectar es aquello que le permite al ser ahí ser justamente lo que la posibilidad le ofrece como tal.

La comprensión dirige al ser ahí en su proyecto según una visión concreta de los caminos que se ofrecen a su libertad. Lo que está comprendido como posibilidad tiene la facultad de desarrollarse. Entonces, la estructura existencial de pro-yecto-arrojado es el fundamento de la comprensión como operación significativa del ser ahí. ${ }^{3}$

El humano, el ser ahí, está en el mundo, se proyecta en y hacia el mundo. Uno de los modos de esa inserción del ser ahí, y tal vez el fundamental, es el habla (lenguaje). La comprensibilidad es siempre ya articulada, incluso antes de la interpretación apropiada. El habla es la articulación de la comprensibilidad. El pensar se hace a través del habla. Todo pensar es ya articulado a través del habla (die Rede), aun cuando no se traduzca en palabras. El lenguaje, o el habla, es el que abre al Dasein al mundo. ${ }^{4}$

Dice Heidegger en su conferencia titulada "El habla":

Suele decirse que el hombre posee el habla por naturaleza. La enseñanza tradicional postula que el hombre, a diferencia de las plantas y

${ }^{1}$ En alemán In der Welt sein. José Gaos lo traduce como ser en el mundo. Por su parte, J. Eduardo Rivera traduce como estar en el mundo. El verbo alemán sein puede traducirse al español como el verbo ser o el verbo estar. Eduardo Rivera aduce que estar en el mundo expresa mejor el sentido de habitar en el mundo y, además, se subraya el aspecto existencial de la estructura del ser del Dasein. Señalamiento que me parece adecuado ( $C f$. Martin Heidegger, Ser y tiempo. Trad. de Jorge Eduardo Rivera. Santiago de Chile, Universitaria, 2002, p. 464).

${ }^{2}$ M. Heidegger, El ser y el tiempo. Trad. de José Gaos. México, FCE, 2000, p. 162.

${ }^{3}$ Hans-Georg Gadamer, El problema de la conciencia histórica. Madrid, Tecnos, 1993, p. 77.

${ }^{4}$ Jorge Eduardo Rivera traduce la palabra alemana Rede como discurso. Dice Heidegger en Ser y tiempo que el fundamento ontológico-existencial del lenguaje es el 
del animal, es el ser viviente capaz de habla. Esta frase no quiere decir solamente que el hombre, además de otras facultades, posee también el hablar. Quiere decir, que solamente el habla capacita al hombre ser aquel viviente que, en tanto que hombre, es. El hombre en tanto que hablante. ${ }^{5}$

Entonces, es el habla a través de lo cual el humano se pro-yecta hacia el mundo. Precisamente, a través del comprender, que articula el habla, el ser ahí se proyecta sobre la posibilidad del estar en el mundo, es decir, existir como posibilidad. ${ }^{6}$

Ahora bien, el ser ahí, el humano, es un ente temporal. Dice Heidegger en Ser y tiempo que el ser ahí es temporal en el "fondo de su ser". ${ }^{7}$ Esta temporalidad, que consiste en la historicidad, es una determinación ontológica del ser ahí. El humano sólo puede comprenderse por las posibilidades de existencia que le abre el mundo el lenguaje. Pero esa apertura sólo puede darse a partir de la herencia que trae consigo el lenguaje. El lenguaje mismo es transmitido por la tradición que es, a la vez, lenguaje. ${ }^{8}$ Pasado, presente y futuro se entrecruzan en el lenguaje. ${ }^{?}$

El estado de yecto, es decir, el estar arrojado al mundo, implica una tradición de posibilidades transmitidas. ${ }^{10}$

El lenguaje, con su dimensión temporal, nos permea, nos traspasa, nos constituye en el sentido de que nos abre las posibilidades en nuestro estar en

habla. Y que el habla es la articulación de la compresibilidad del estar en el mundo (M. Heidegger, Ser y tiempo, p. 184).

${ }^{5}$ M. Heidegger, "El habla", en De camino al habla. Barcelona, Serbal, 2002, p. 9.

${ }^{6} \mathrm{M}$. Heidegger, El ser y el tiempo, p. 418.

${ }^{7}$ Ibid., p. 497.

${ }^{8}$ María Antonia González Valerio, "Rememoración y tradición: la hermenéutica entre Heidegger y Gadamer”, en Signos Filosóficos, núm. 10. México, UAM-Iztapalapa, julio-diciembre, 2003 , p. 88.

${ }^{9}$ Dice Heidegger en Ser y tiempo que el cuidado (Sorge), es decir, la anticipación del Dasein en su estar en el mundo ("anticiparse-a-sí-estando-ya en-el-mundo" o "pre-ser-seya-en el mundo"), es temporal y tiene varios momentos estructurales: a) el comprender, b) la disposición afectiva, c) la caída y d) el discurso. 1. A través del comprender el Dasein puede desarrollar sus posibilidades del mirar en torno o del contemplar. Es el "proyectante estar vuelto hacia un poder-ser por mor del cual el Dasein existe cada vez". El comprender se fundamenta en el futuro; 2 . Este comprender siempre se hace desde una disposición afectiva, un estado de ánimo y se temporiza en el pasado (habersido); 3. La caída, el extrañamiento del Dasein en que se le oculta su poder ser, tiene sentido en el presente; 4. Finalmente, el discurso (habla) es el que articula la apertura al mundo, constituida por el comprender, la disposición afectiva y la caída (M. Heidegger, Ser y tiempo, pp. 157-158).

${ }^{10}$ M. Heidegger, El ser y el tiempo, p. 414. 
el mundo. El lenguaje constituye la tradición, lo que se hereda y que es parte constitutiva del humano, del Dasein. Todo lo que pensamos, lo pensamos desde una tradición. Dice el mismo Heidegger: "De cualquier modo que intentemos pensar, y pensemos lo que pensemos, pensamos en el campo de la tradición. Ésta prevalece cuando nos libera del pensar en lo pasado para pensar por adelantado, lo que ya no es ningún planear. Sólo cuando nos volvemos con el pensar hacia lo ya pensado, estamos al servicio de lo por pensar". ${ }^{11}$

Entonces, ¿por qué reflexionar sobre la tradición?, porque los humanos somos tradición, somos historicidad.

La palabra tradición, del latín traditio, traditionis, significa entrega, lo que se nos da. Precisamente, lo que heredamos. Pero ese heredar es una acción activa, es decir, lo que adquirimos en la rememoración. ${ }^{12}$ Es algo que constituye nuestra propia existencia, pero que se encuentra en constante transformación. Señala Gadamer que:

[...] como seres finitos, estamos en tradiciones, independientemente de si las conocemos o no, de si somos conscientes de ellas o estamos lo bastante ofuscados como para creer que estamos volviendo a empezar (ello no altera en nada el poder que la tradición ejerce sobre nosotros). Pero sí que cambia algo en nuestro conocimiento si arrastramos las tradiciones en las que estamos y las posibilidades que nos brinda para el futuro, o si uno se figura que puede apartarse del futuro hacia el cual estamos viviendo ya, programar y construir todo de nuevo. Por supuesto, tradición no quiere decir mera conservación, sino transmisión. Pero la transmisión no implica dejar lo antiguo intacto, limitándose a conservarlo, sino aprender a concebirlo y decirlo de nuevo. ${ }^{13}$

Me gustaría destacar la última parte de la cita anterior: la transmisión no implica dejar lo antiguo intacto. La tradición no es algo a lo que tengamos acceso in-mediatamente. Su acceso está precisamente mediado por la misma tradición, por el lenguaje, el habla, que es la tradición.

Nuestra vida cotidiana es un caminar en la simultaneidad del pasado y del futuro. Un futuro como horizonte abierto y un pasado como algo irrepetible. ${ }^{14}$ La tradición corre entre esos dos horizontes. La tradición debe ser interpretada.

${ }^{11}$ M. Heidegger, Identidad y diferencia. Barcelona, Ánthropos, 1990, p. 97.

12 Rememorar es el acto de traer a la memoria (Andenken) el pensamiento ya pensado, lo que implica el acto de recuperar el pasado a través de su distorsión y recuperación (M. A. González Valerio, "Rememoración y tradición: La hermenéutica entre Heidegger y Gadamer", en op. cit., pp. 90-92).

${ }^{13}$ H.-G. Gadamer, La actualidad de lo bello. Barcelona, Paidós, 1991, p. 116.

${ }^{14}$ Ibid., pp. 41-42. 
Interpretar es encontrar las posibilidades propias al interior de la tradición que soy y estoy, que ha pasado, pero que opera en el presente propio. ${ }^{15}$

Gadamer señala que la investigación histórica, misma que es interpretación, está "soportada" por el movimiento histórico en que se encuentra esa misma reflexión histórica. ${ }^{16}$ Por lo tanto, esta reflexión no puede estar orientada "teleológicamente" desde el objeto hacia el que se dirige la investigación. Se necesita de un proceso hermenéutico para la reflexión histórica, el cual supone una fusión de horizontes, la relación dialéctica entre pasado y presente, entre la tradición que produce el texto ${ }^{17}$ y la tradición que reflexiona sobre el texto. Esto quiere decir que la reflexión histórica requiere, como acción fundamental, la comprensión de la tradición y un desplazamiento hacia el acontecer de la tradición en que es producido un texto. ${ }^{18}$ En el acto de comprensión, como conciencia histórica, se experimenta por sí misma la relación de tensión entre el texto que supone una tradición, y la mirada desde el presente. Precisamente, en palabras de Gadamer, la "tarea hermenéutica consiste en no ocultar esta tensión en una asimilación ingenua, sino en desarrollarla conscientemente". ${ }^{19}$ Una verdadera comprensión significa recuperar los conceptos de un pasado histórico de manera que se contenga, en esta recuperación, nuestro propio concebir. Entonces, en el caso específico de la filosofía, la reconstrucción de las preguntas que animaron las respuestas filosóficas pasa a nuestro propio preguntar, es decir, sólo adquieren sentido a través de nuestro cuestionamiento.

\section{Tradición, hermenéutica e historia de la filosofía mexicana}

Quiero comenzar este apartado con una cita de Mario Magallón que me parece coincide con lo hasta aquí dicho:

${ }^{15}$ Félix Duque, Los destinos de la tradición. Filosofía de la historia de la filosofía. Barcelona, Ánthropos, 1989, pp. 138-139.

${ }^{16}$ H.-G. Gadamer, Verdad y método. Salamanca, Sígueme, 2005, vol. 1, p. 353.

17 Aquí debe entenderse texto en un sentido amplio, como lenguaje, el cual es siempre diálogo. Ricoeur señala que la noción de texto implica lo escrito, el diálogo y la significación. Dice este autor que el escrito surge como un discurso con "intención de decir" y que ese escrito es la inscripción directa de esa intención, es decir, tiene una intención dialógica y que a la vez requiere de la significación (Paul Ricoeur, "What is a Text? Explanation and Understanding", en Hermeneutics and the Human Sciences. Ed. de J. B. Thompson. Nueva York, Universidad de Cambridge, 1998, p. 147).

${ }^{18}$ Gadamer precisa sobre el acto de la comprensión, que ésta debe "pensarse menos como una acción de la subjetividad que como un desplazarse uno mismo hacia un acontecer de la tradición, en que el pasado y el presente se hallan en continua mediación" (H.-G. Gadamer, Verdad y método, vol. 1, p. 360).

${ }^{19}$ Ibid., p. 377. 
Sabido es, desde la época moderna, que el hombre es historia, es temporalidad, es circunstancialidad: porque en ella se muestra su continuo hacerse y desarrollarse; es el ente que se "es", por haber sido de algún modo esto o aquello. [...] El hombre es en su existencia un constante hacerse, un proyecto y compresión de la posibilidad peculiar de desarrollarse; proyección de un sentido que por circunstancialidad e historicidad es tiempo continuo dialécticamente prolongado por su "gestar histórico" pues lo propio del hombre es la historia. Pero ¿esta historia ha sido común a todos los hombres y sociedades? Vista en el marco de aquella concepción europea, la respuesta en definitiva es no $[\ldots]^{20}$

Creo que ha quedado clara la idea de que la tradición, la historia, la historicidad, es un componente ontológico de nuestra existencia humana. Historia puede ser entendida como circunstancia, que es también tradición.

Pensar la filosofía a través de la tradición, de la circunstancialidad, es hacer historia de la filosofía y filosofía de la historiografía de la filosofía. Para ello se necesita de un reflexionar filosófico que cumpla una función interpretativa a través de criterios metodológicos y epistemológicos, a través de la hermenéutica, como lo señalaba Gadamer. Es ésta la que permitirá el esclarecimiento y guiará las operaciones que posibiliten entender e interpretar los textos o documentos. ${ }^{21}$ En otras palabras, la hermenéutica busca comprender el texto por medio de una crítica aplicada como epistemología al texto. ${ }^{22}$

Ahora bien, hago las preguntas: ¿por qué reflexionar sobre la tradición filosófica? y ¿por qué reflexionar sobre la historia de la filosofía?; o haciendo estas preguntas más concretas: ¿por qué reflexionar sobre nuestra tradición filosófica? y ¿por qué reflexionar sobre la historia de la filosofía mexicana?

Reflexionar sobre la historia de la filosofía a través de la circunstancialidad, de la tradición, implica un ejercicio de conocernos a nosotros mismos, conocer "nuestra apertura", nuestra posibilidad del propio filosofar. Como se ha señalado más arriba, el no conocer, el no querer conocer, el ignorar o el

${ }^{20}$ Mario Magallón Anaya, Dialéctica de la filosofía latinoamericana. Una filosofía en la historia. México, UNAM, CCyDEL, 1991, p. 131.

${ }^{21}$ Mauricio Beuchot, Historia de la filosofía en el México colonial. Barcelona, Herder, 1996, p. 14.

${ }^{22}$ Se puede entender por hermenéutica: "el arte y ciencia de interpretar textos, entendiendo por textos aquellos que van más allá de la palabra y el enunciado. Son por ello, textos hiperfrásticos, es decir, mayores que la frase. [...] La hermenéutica interviene donde no hay un solo sentido, es decir, donde hay polisemia. [...] La hermenéutica, pues, en cierta manera, descontextualiza para recontextualizar, llega a la contextualización después de una labor elucidatoria y hasta analítica" (M. Beuchot, Tratado de hermenéutica analógica. Hacia un nuevo modelo de interpretación. México, UNAM, FFL/Itaca, 2005, pp. 13-14). 
negar la propia tradición, no implica que no se esté en ella y que no se piense a través de ella.

Dice Ortega y Gasset:

[...] hacemos siempre nuestra filosofía dentro de tradiciones determinadas de pensamiento en las cuales nos hallamos tan sumergidos que son para nosotros la realidad misma, y no las reconocemos como particulares tendencias o ensayos de la mente humana que no son los únicos posibles. Sólo estaremos en la plena posesión de estas tradiciones, que son como nuestro subsuelo intelectual, si las sabemos bien, en sus más decisivos secretos, poniendo al descubierto sus más "evidentes supuestos". ${ }^{23}$

Se debe de comprender que las ideas filosóficas se producen en circunstancias determinadas para responder a problemas específicos que se generan en esas mismas circunstancias. Asimismo, se debe comprender, con el mismo Ortega y Gasset, que pensar es dialogar con las circunstancias. ${ }^{24}$

La razón, el logos, sólo existe real e históricamente. No es una entidad trascendente que se basta así misma, que es universal y a-histórica. Siempre está referida a lo dado sobre lo que se ejerce. ${ }^{25}$

La tradición no es la limitación del filosofar, es su posibilidad. Pensar dentro de una tradición filosófica propia no implica la inadecuada idea de que

${ }^{23}$ José Ortega y Gasset, Historia como sistema. Madrid, Espasa-Calpe, 1971, p. 112.

${ }^{24}$ Ibid., p. 95.

${ }^{25}$ Incluso las teorías metafísicas y ontológicas que se elaboran con la pretensión de ser universales, provienen de situaciones históricas contingentes y concretas. Al respecto se puede referir a Gianni Vattimo, quien señala: "Es cierto de todas las filosofías que, en alguna medida, ellas, si no son explícitas 'ontologías de la actualidad' (lo que es cierto al menos para las filosofias posteriores a Hegel, como ha dicho también Habermas), son siempre respuestas a preguntas contingentes. Así, por ejemplo, la misma filosofía trascendental kantiana nació de responder, por una parte, a una exigencias de fundamentación de la validez universal del saber que había madurado en el curso de la revolución científica moderna, y por otra, a una exigencia de defensa de las 'razones del alma', también profundamente ligada a esa misma revolución científica. Aún más: los orígenes de la hermenéutica, como lo ha mostrado Dilthey, están profundamente ligados a los problemas religiosos, sociales y políticos surgidos con la Reforma protestante. En fin, el existencialismo del presente siglo [siglo xx], y antes que él la crisis del neokantismo, no son pensables fuera del marco histórico caracterizado por las primeras muestras de la sociedad de masas que son perceptibles en el Nietzsche de la segunda Consideración intempestiva, pero aun antes en el individualismo kierkegaardiano, por el nacimiento de la antropología cultural y por la crisis de los fundamentos de la ciencia" (Gianni Vattimo, Más allá de la interpretación. Barcelona, Paidós/Universidad Autónoma de Barcelona, 1995, pp. 47-48). 
sólo se pueden reflexionar problemas locales. Se deben pensar los problemas universales, problemas que competen a todos los humanos. Pero la única vía, por razones ontológicas y epistemológicas anteriormente expuestas, es a través de la particularidad que implica la propia tradición. Insisto, tener y asumir una tradición filosófica no significa hacer únicamente planteamientos filosóficos particulares, ni utilizar sólo conceptos filosóficos locales. Significa una adopción y apertura a marcos teóricos-conceptuales de pensamiento de distintas tradiciones desde la propia tradición. Esto sólo se puede hacer si estos marcos teóricos y conceptuales adquieren sentido y significación en la tradición propia.

La filosofía, en una tradición específica, puede reflexionar sobre cualquier tipo de problemas, pero desde el marco de la tradición propia. Según Leopoldo Zea, la filosofía que pretenda ser Filosofía debe plantearse bajo la preocupación de problemas de carácter universal, es decir, problemas que son comunes a todos los humanos por el hecho de ser humanos. ${ }^{26}$ Dentro de esta perspectiva la Filosofía que desarrollemos dentro de nuestra tradición filosófica mexicana o latinoamericana debe abarcar e incluirse en la reflexión de problemas comunes a toda la filosofía.

En esta misma perspectiva, hacer historia de la filosofía es un proceso de autoconocimiento del mismo pensamiento; es conocer la tradición desde la cual filosofamos, que podemos negar, ignorar o desconocer, pero que siempre está ahí como telón de nuestra reflexión. Hacer historia de la filosofía es hacer la rememoración de la tradición filosófica desde la cual estamos filosofando, desde la cual los filósofos concretos hacemos filosofía concreta.

Señalaba muy atinadamente Arturo Andrés Roig que después de Hegel hacer historia de la filosofía es en sí mismo hacer filosofía, y que la filosofía consiste en una praxis. ${ }^{27}$ Roig está de acuerdo con Hegel cuando propone que la filosofía es un faciendum (haciendo, construyendo) y no un factum (un hecho). Sin embargo, con lo que no está de acuerdo el filósofo argentino con la perspectiva de la filosofía de la historia de Hegel, es el rechazo de este último a la contingencia, es decir, la afirmación de que hay un único sistema

${ }^{26} \mathrm{Cf}$. Leopoldo Zea, En torno a una filosofía americana. México, El Colegio de México, 1945, p. 63.

${ }^{27}$ Arturo Andrés Roig, Teoría y crítica del pensamiento latinoamericano. México, FCE, 1981, p. 86. Para Hegel, la filosofía es un sistema en evolución, y esta evolución estaba sustentada en la historia misma de la filosofía. La filosofía es una marcha progresista a través de una serie de fases y momentos de evolución que se encaminaban teleológicamente. Por lo tanto, hacer historia de la filosofía era hacer filosofía, en ese reconocimiento de la evolución de la idea hacia el saber absoluto que supone la misma filosofía. De esta forma sentencia Hegel: "el estudio de la historia de la filosofía es el estudio de la filosofía misma y no podía ser de otro modo" (G. W. F. Hegel, Lecciones sobre la historia de la filosofía. México, FCE, 2002, vol. 1, p. 34). 
posible que funciona como a priori absoluto y que se encuentra contenido en el Espíritu Absoluto. ${ }^{28}$ Lo que implicaría que sólo existe una sola filosofía. Y lo que resulta de esta visión, es la supeditación de la historia de la filosofía a un esquema de una lógica en la que se cree poder someter toda forma de pensamiento a una necesidad silogística. ${ }^{29}$ Desde esta perspectiva, la subjetividad, y lo que llama Roig "a priori antropológico", quedan anulados y absorbidos. Roig llama "a priori antropológico" a la voluntad de un sujeto de ponerse a sí mismo como sujeto. El ponerse implica el rescate de la cotidianidad. ${ }^{30} \mathrm{Y}$, precisamente, éste es el principio de todo filosofar y de cualquier reflexión sobre la historia de la filosofía. Dice Roig al respecto: "El a priori antropológico es el acto de un sujeto empírico para el cual su temporalidad no se funda ni en el movimiento del concepto, ni en el desplazamiento lógico de una esencia a otra" ${ }^{31}$ Como sujeto empírico es contingente y determinado, viviente, volitivo e intencionado. Como he señalado más arriba, es un sujeto circunstancial. Estos señalamientos son de suma importancia para poder precisar el concepto de tradición filosófica y su aplicación a la historia de la filosofía.

Ahora bien, la rememoración de la tradición tiene que obedecer a la dinámica y al marco conceptual de la misma tradición. No se puede violentar esa historicidad que es la tradición y que, a final de cuentas, somos nosotros. No se deben utilizar marcos conceptuales que se pretendan universales al hacer historia de la filosofía. ${ }^{32}$ No es posible negar que todas las tradiciones filosóficas tengan en común problemas, temas, métodos, metodologías de análisis, problemáticas ontológicas y epistemológicas, pero esto no implica que existan categorías de análisis universales para la filosofía misma y para su historia. ${ }^{33}$

Decía José Gaos que al ejercicio filosófico, el ejercicio de la razón, se le impone la tarea de estudiar la vida propia, pero con su radical historicismo de la misma filosofia. ${ }^{34}$ Estudiar la filosofía con su historia, la historia que es la realidad de la historicidad humana. ${ }^{35}$ Y si se acepta esta premisa, el ejercicio

${ }^{28}$ A. A. Roig, op. cit., p. 98.

${ }^{29}$ Idem.

${ }^{30}$ Ibid., p. 12.

${ }^{31}$ Idem.

${ }^{32} \mathrm{Al}$ respecto de este problema referido al caso de la filosofía latinoamericana puede consultarse el interesante debate entre Augusto Salazar Bondy (Existe una filosofía de nuestra América? México, Siglo XXI, 1988) y Leopoldo Zea (La filosofía americana como filosofía sin más. México, Siglo XXI, 2007).

${ }^{33} \mathrm{Cf}$. M. Magallón Anaya, Filosofía, tradición, cultura y modernidad desde América Latina. Culiacán, Universidad Autónoma de Sinaloa, 2008, pp. 13 y ss.

${ }^{34}$ José Gaos, "El pensamiento hispano-americano. Notas para una interpretación histórico-filosófica", en Obras completas. VI. Pensamiento de lengua española. Pensamiento español. México, UNAM, 1990, p. 33.

${ }^{35}$ Idem. 
filosófico tiene que reflexionar sobre la situación histórica concreta del lugar y del tiempo desde donde se filosofa.

En el caso concreto que nos atañe, somos mexicanos y también somos latinoamericanos. No afirmo lo anterior por un nacionalismo ramplón, sino por las razones ontológicas anteriormente expuestas. Estamos dentro de la tradición filosófica mexicana, y en un grado de más generalidad, estamos dentro de la tradición filosófica latinoamericana, nos guste o no, lo aceptemos o no, lo afirmemos o lo neguemos.

En esta situación es necesario rememorar nuestro pasado filosófico, recuperar nuestra tradición filosófica, a través de una teoría hermenéutica que debe incluir una reflexión sobre la filosofía de la historia y de la historia de la filosofía.

En este sentido, la propuesta que hace Mauricio Beuchot al respecto de la filosofía mexicana resulta sumamente interesante: "La influencia que se espera de la filosofía en México, dependerá de la misma idea de filosofía que tengamos". ${ }^{36}$ Continúa explicando que es necesario hacer filosofía política basándola en una ética, para lo cual se necesita una antropología filosófica, y para ello se necesita la ontología, la epistemología, la filosofía de la historia y hasta la ética. ${ }^{37}$ En su perspectiva, la filosofía de la historia es de suma importancia para criticar el modo como se ha escrito la historia de la filosofía en México. Esto no sólo en un ángulo referencial, es decir, para ver con cuanta certeza se ha hecho, sino que también desde un ángulo de sentido, para ver qué significaciones se le han dado. ${ }^{38}$ A lo anterior añado, la importancia de hacer historia de la filosofía también se encuentra en determinar qué significaciones y qué determinaciones se le pueden dar a la misma filosofía.

Nuestra tradición filosófica mexicana, como lo señala Carmen Rovira, está conformada de un pensamiento "a veces confuso y falto de rigor", pero que es valioso por lo que posibilita a nuestro filosofar, ${ }^{39}$ por la apertura que da a nuestro filosofar.

\section{Consideraciones finales}

Creo haber dado argumentos suficientes para precisar una noción del concepto de tradición que implica un fundamento ontológico y epistemológico. Los

${ }^{36}$ M. Beuchot, "La función de la filosofía en México", en La filosofía mexicana ¿incide en la sociedad actual? México, Torres Asociados, 2008, p. 69.

${ }^{37}$ Idem.

${ }^{38}$ Idem.

${ }^{39}$ María del Carmen Rovira Gaspar, "¿Nuevas rutas en la filosofía en México en el siglo XXI?”, en Mario Miranda y Norma Delia Durán, coords., La filosofía mexicana entre dos milenios. México, UNAM, FFL, DEGAPA, 2002, p. 40. 
humanos somos historicidad, somos tradición. Ésta es una determinación de nuestra existencia. Así, la tradición es a la vez lenguaje, y ésta es la forma de proyectarnos hacia el mundo, en nuestro estar en el mundo.

Este concepto sirve para fundamentar, en primer lugar, la necesidad de la reflexión sobre la historia de la filosofía, y, en segundo lugar, la historia de la filosofía mexicana como actos de autoconocimiento, en la medida en que estamos y vivimos en una tradición específica. La rememoración de ésta se vuelve una tarea necesaria y determinante en nuestro quehacer filosófico actual.

Cuestiones de igual importancia y relevancia tienen que ver con la metodología de esa filosofía de la historia y de la historia de la filosofía que deben estar presentes en nuestra reflexión filosófica. ${ }^{40}$

Para finalizar, quiero proponer otra implicación para nuestro quehacer filosófico que trae consigo el estudio y la reflexión sobre la propia tradición. El conocer la circunstancia en la que se ha desarrollado y se desarrolla nuestra tradición implica un ejercicio de recuperación histórica, de memorización. Decía José Gaos en 1943 que "la reflexión del pensamiento hispano-americano sobre sí mismo entraña una reflexión sobre Hispano-América" ${ }^{41}$ ¿Qué quiere decir esto? Si se quiere hacer una historia de la filosofía hispanoamericana, una rememoración de la tradición filosófica hispanoamericana, debemos filosofar sobre nuestra situación histórica concreta; debemos reflexionar sobre los problemas históricos de Hispanoamérica en general y de México en particular. Esta reflexión debe estar acompañada por la característica esencial de la filosofía que es la crítica. ¿Qué implica esto? Implica un posicionamiento desde el cual dirigir esa mirada crítica. La filosofía, con la determinación de su tradición, implica un compromiso ético, un compromiso de praxis, un compromiso transformador y liberador. ${ }^{42}$

${ }^{40}$ A este respecto existen variados y valiosos esfuerzos. Filósofos mexicanos y latinoamericanos que se han ocupado y que se ocupan en construir una teoría general de la historia de la filosofía y de su metodología.

${ }^{41}$ J. Gaos, "Significación filosófica del pensamiento hispano-americano (notas para una interpretación histórico-filosófica)", en Cuadernos Americanos. México, UNAM, marzo-abril, 1943, vol. vIII, núm. 2, p. 82.

${ }^{42}$ El sentido de utilidad y practicidad es una exigencia de la filosofía moderna. Puede pensarse en la exigencia de utilidad en la filosofía cartesiana. Se puede señalar la crítica que establece Descartes contra la filosofía especulativa: "en lugar de esta filosofía especulativa que se enseña en las escuelas se podría encontrar una práctica mediante la cual, conociendo la fuerza y las acciones del fuego, del agua, del aire, de los astros, de los cielos y de todos los demás cuerpos que nos rodean, tan claramente como conocemos diversos oficios de nuestros artesanos, podríamos emplearlos del mismo modo en todos los usos para que sean propios, y, de ese modo, convertirnos en dueños y señores de la naturaleza, cosa que no sólo es de desear por la invención de una infinidad de artificios que harían que gozásemos sin ningún trabajo de los frutos de la tierra y de todas las co- 
Todo pensar, todo filosofar, implica en sí mismo un posicionamiento político ${ }^{43}$ precisamente por el peso de la historia y de la tradición. Entonces, el filósofo mexicano o latinoamericano tiene que asumir ese posicionamiento y de esta forma responder a sus exigencias históricas en vías de una trasformación social. Gran parte de estas exigencias deben buscarse en la rememoración histórica, lo que implica también la rememoración de la historia de la filosofía.

modidades que en ella se encuentran, sino, principalmente también, por la conservación de la salud que es indudablemente el primer bien y el fundamento de todos los demás bienes de esta vida" (René Descartes, Discurso del método. Madrid, Edaf, 1998, p. 93). Y en otra parte continúa: "Este modo de filosofar [especulativo] es siempre muy cómodo para las personas medianías; porque la oscuridad de las distinciones de los principios de los que se sirven es causa de que puedan hablar de todo tan atrevidamente como si supieran sostener cuanto dicen contra los más sutiles y hábiles, y sin que haya medio de convencerlos nunca" (ibid. p. 100).

${ }^{43}$ Debe entenderse lo político en el sentido más amplio, como nuestra posición, consciente e inconsciente, en el entramado de relaciones sociales y culturales de una determinada comunidad. 